DOI: 10.14526/2070-4798-2019-14-3-35-39

\title{
Improvement of 15-17-year-old volleyball players sports training based on correction of leading techniques
}

\author{
Nadezhda V. Makarova ${ }^{1 *}$, Aleksey I. Kardashevskiy ${ }^{2}$, Evgeniya G. Kozhevnikova ${ }^{2}$ \\ ${ }^{1}$ Pskov State University \\ Pskov, Russia \\ ORCID: oooo-0oo2-7446-118X, avramova-84@mail.ru* \\ ${ }^{2}$ Samara State Technical University \\ Samara, Russia \\ ORCID: oooo-ooo1-7066-3676, Aik1780@yandex.ru \\ ORCID: oooo-0oo2-5294-6143, kozheg@mail.ru
}

\begin{abstract}
This research paper studies the prime factors which characterize and raise the efficiency of volleyball players competitive activity. Increase of sports training effectiveness and resulting quality of volleyball players competitions requires a steady growth of their motorial potential for the variability in use of sport techniques. The main peculiarity of training a women's team is correction of players sports techniques both individually and for group actions. Materials and methods. The volleyball players of $15^{-17}$ years of age sports school participated in the experiment. To investigate theoretical aspects of volleyball players sports training correction we used the analysis of scientific--methodical and special literature, and also expert evaluation of volleyball players sports techniques by relevance. Result. The principal leading sports techniques of volleyball players are the following: serve, pass, attack, reception and block; each of them has its own content, types and conditions of execution. It is mentioned that structural adjustment of interrelation between volleyball techniques, performed by highly skilled volleyball sportswomen, happens depending on the game situation. It was found out that the specific weight of each sports technique of volleyball players is conditional on the game situation. As the sports skills of volleyball players improve in course of time, there also occurs a change in the game picture towards increase in dynamism and qualification. We determined conditions for correcting sports techniques and developed a criteria scale for evaluation of volleyball players technical methods correcting. Conclusion. The main condition for correction of volleyball players techniques is determination and evaluation of the orientation level on the sports ground, depending on the game situation and development of their speed-and-power and strength qualities on a scale from one to five points, where the level of maturity and effectiveness of combination of power and speedand-power characteristics is estimated. The developed criteria scale for evaluation of volleyball players' techniques demonstration in the course of game situations allows to improve technical methods promptly owing to correction of their use in combination of strength demonstration efforts and speed-power qualities in the process of play. Further perfections of sports techniques contribute to the increase in efficiency of volleyball players competitive activity.
\end{abstract}

Keywords: sports training, volleyball, correction, sports techniques, rating scale.

For citation: Nadezhda V. Makarova*, Aleksey I. Kardashevskiy, Evgeniya G. Kozhevnikova. Improvement of sports training of 15-17-year-old volleyball players based on correction of leading techniques. Russian Journal of Physical Education and Sport. 2019; 14(3): 35-39. DOI: 10.14526/2070-4798-2019-14-3-35-39

\section{INTRODUCTION}

The current trend of volleyball development is connected with the growing popularity of this sport among young people. Volleyball is considered as a team situational sport with the demonstration of different pace of play. It is characterized by the growth of a high dynamism and qualification of players. They are capable of moving actively on the sports ground and at the same time solving various motor issues. The degree of technical and tactical preparedness of players of different skill levels has changed. Therefore, this thesis requires to prepare the player for the team with the correction of sports techniques acceptable to this team within a short period of time. Increase of sports training effectiveness and resulting quality of volleyball players competitions requires a steady growth of their motorial potential for the variability in use of sport techniques. The main peculiarity of training a women's team is correction of players sports 
techniques both individually and for group actions.

Analysis of specialists' research studies allowed to discover different approaches to the development of volleyball players professional preparing problem.

N.V. Avramova draws special attention to the problems of improving the efficiency of volleyball players on the basis of forming the ability of their own motor actions $[1,2,3]$.

V.K. Balsevich lays great emphasis on the development of sports training process organization principles underlining such principal directions of improvement as: formation for self-improvement; improvement of physical and keniziological potential; creation of team spirit.

The principal component of volleyball players technical training is to improve the game activity by means of correcting sport techniques.

O.V. Demidenko proposes to use modeling of the developing movement accuracy process in volleyball players as a condition for increasing effectiveness of game actions.

Judging by the opinion of O.V. Demidenko, efficiency of volleyball players game actions may depend on the quality of the movements final phase with the ball. The author pays attention to the necessity of examining accuracy in reproduction of spatio-temporal and spatio-power parameters of motor acts; precision in movements of the body, its certain parts and components in response to external stimulus; accuracy in differentiation of muscular efforts; precision in ballistic motions.

One of the most significant factors in perfection of 15-17 year-old volleyball players sports training, on the basis of leading techniques correction, is to improve physical qualities, especially those ones which have respect to motor coordination.

E.G. Glinskaya suggests methods of improving volleyball techniques in the initial stages of training as a basis for acquiring the leading technical methods of a volleyball player.

M.V. Denisov regards the importance of the conjugate method as a factor which contributes to the optimization of the improving volleyball technique elements process.

Execution of various sports techniques basically forms the content of the entire volleyball game. High-quality execution of volleyball techniques by each player has a great influence on the successful result of the whole game. However, the foundation of success is composed of all aspects of training volleyball players, namely physical, technical and tactical, functional and psychological. The state of readiness to overcome obstacles and difficulties may also become an important factor.

G.A. Kamaliyeva considers the difficulties, arising unexpectedly in the competitive activity, and offers a method of intellectual tasks in the process of preparing training exercises for volleyball players and main strategies for improving their competitive activity.

All the above-mentioned theses suggest reconsideration of volleyball players existing techniques and development of training exercises for their improvement.

The purpose of this research work is the substantiation of experimental methods development for the correction of 15 - 17-year-old volleyball players' sports techniques.

\section{MATERIALS AND METHODS}

The volleyball players of 15-17 years of age sports school participated in the experiment. To investigate theoretical aspects of volleyball players' sports training correction we used the analysis of scientific-and-methodical and special literature, and also expert evaluation of volleyball players sports techniques by relevance.

\section{RESULTS AND DISCUSSION}

The principal leading sports techniques of volleyball players are the following: serve, pass, attack, reception and block; each of them has its own content, types and conditions of execution.

Figure 1 clearly shows the hierarchy of volleyball players sports techniques

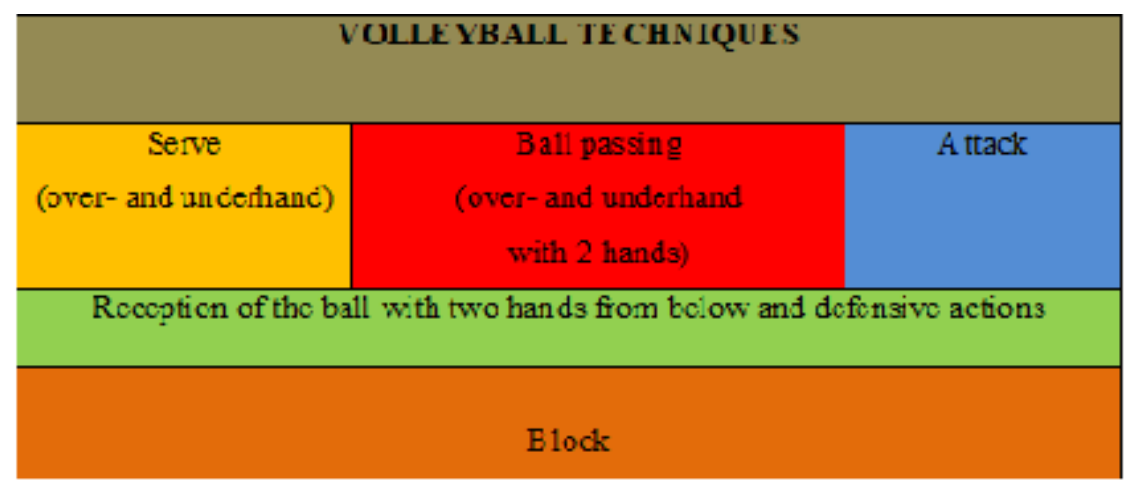

Fig.1. Classification of volleyball techniques 
At the first stage of our research, we conducted a survey of volleyball players to determine the significance of each volleyball technique on a scale from one to five points.
The results of techniques significance expert evaluation are presented in Table 1.

Table 1 - Results of the volleyball players' techniques significance expert evaluation.

\begin{tabular}{|c|c|c|c|c|c|c|c|}
\hline \multirow{2}{*}{ No. } & \multirow{2}{*}{ Volleyball techniques } & \multicolumn{7}{|c|}{ Experts } \\
\cline { 3 - 8 } & & 1 & 2 & 3 & 4 & 5 & Total points \\
\hline 1 & Ball serve & 5 & 5 & 5 & 5 & 5 & 25 \\
\hline 2 & Ball pass & 3 & 4 & 3 & 4 & 5 & 19 \\
\hline 3 & Attack & 5 & 4 & 4 & 4 & 5 & 22 \\
\hline 4 & Ball reception & 4 & 5 & 5 & 5 & 5 & 24 \\
\hline 5 & Block & 5 & 4 & 4 & 5 & 4 & 22 \\
\hline
\end{tabular}

Results analysis concerning expert evaluation of the highly-qualified volleyball players' techniques significance showed that the first place regarding the number of points is taken by "Ball serve", the second - by "Ball reception". Such volleyball techniques as "Attack" and "Block" share the third place. The fifth place was given to "Ball pass".

The questionnaire survey of the necessity to correct the sports techniques of volleyball players according to the game situation also caught the interest of specialists.

Examining peculiar properties of volleyball players competitive activity we revealed the ratio of techniques executed by highly skilled volleyball players in the game.

It is mentioned that structural adjustment of interrelation between volleyball techniques, performed by highly skilled volleyball sportswomen, happens depending on the game situation. It was found out that the specific weight of each sports technique of volleyball players is conditional on the game situation. It is revealed that the specific weight of each technical skill of volleyball players depends on the game situation. As the sports skills of volleyball players improve in course of time, there also occurs a change in the game picture towards increase in dynamism and qualification.

The formation of techniques regarding orientation on the sports ground depending on the game situation can be considered the first condition for the correction of technical skills. This is achieved on condition that volleyball players solve intellectual tasks during training. Formation of orientation skills under the changing game conditions allows to carry out quick correction of techniques. For successful development of volleyball players' orientation skills on the sports ground during the game, we offer to include such training tasks into the game process which contain deception maneuvers from outside and within a team of players.

The second condition for the correction of techniques is the formation of orientation skills in standard conditions of the game. It is required to practice them in competitive activity, so that sportswomen keep them in memory and perform them automatically.

As the third condition for the correction of techniques we can name the record speed and strength qualities indicators that ensure the effectiveness of executing special techniques by volleyball players. The main condition for the implementation is determination and evaluation of the volleyball players speed power and strength qualities development level on a scale from one to five points, which mainly evaluates the success of combining the demonstration of power and speed qualities of an athlete.

Table 2 given below represents a scale of criteria for evaluation of volleyball players' techniques correction.

\section{CONCLUSION}

Thus, for improvement of 15-17-year-old volleyball players' sports training on the basis of the leading volleyball techniques correction it is necessary to study structural transformation of technical skills ratio depending on a game situation. It was found out that the specific weight of each sports technique of volleyball players is conditional on the game situation. We determined the following conditions for correcting volleyball skills: formation of techniques regarding orientation on the sports ground depending on the game situation; formation of orientation skills in standard conditions of the game; record of speed and strength qualities indicators that ensure the effectiveness of executing special techniques by volleyball players.

The developed scale of criteria for assessing the manifestation of volleyball players' technical techniques in the process of game situations in a timely manner allows to improve the techniques by correcting the use of effort, strength and speedpower qualities combinations in the game. Further improvement of techniques contributes to improving the efficiency of volleyball players' competitive activities. The developed criteria scale for evaluation 
of volleyball players' techniques demonstration in the course of game situations allows to improve technical methods promptly owing to correction of their use in combination of strength demonstration efforts and speed-power qualities in the process of play.

Table 2 - Criteria for evaluation of volleyball players correcting techniques

\begin{tabular}{|c|l|l|}
\hline Evaluation criteria & Points & \multicolumn{1}{|c|}{ Description of criterion } \\
\hline "Excellent" & 5 (five) & $\begin{array}{l}\text { If an athlete demonstrates muscular efforts when performing } \\
\text { volleyball techniques (serve, reception, attack, block), he } \\
\text { also shows a high level of spatial orientation in game and } \\
\text { standard situations and applies muscular efforts for technical } \\
\text { performance of the motor action of the volleyball player } \\
\text { adequately, with high degree of successfulness. }\end{array}$ \\
\hline "Good" & $\begin{array}{l}\text { An athlete demonstrates a good level of muscle efforts in } \\
\text { execution of volleyball techniques and in spatial orientation } \\
\text { in game and standard situations; adequately and with a } \\
\text { high degree of successfulness he applies muscular efforts to } \\
\text { perform a skillful motor action of the volleyball player showing } \\
\text { rational combination of power and speed-power qualities when } \\
\text { performing the corresponding techniques. }\end{array}$ \\
\hline "Satisfactorily" & 3 (three) & $\begin{array}{l}\text { Shows a satisfactory level of muscular efforts when performing } \\
\text { volleyball techniques and in certain episodes of game and } \\
\text { standard situations; adequately and with a low accuracy he } \\
\text { applies muscular efforts for technical execution of motor action } \\
\text { when carrying out the corresponding techniques in combination } \\
\text { of power and speed-power qualities; there are some difficulties } \\
\text { in the implementation of speed-power qualities depending } \\
\text { on the complexity of the technical skill and the arisen game } \\
\text { situation. }\end{array}$ \\
\hline "Very bad" & $\begin{array}{l}\text { Lack of muscular efforts coordination when performing } \\
\text { volleyball techniques, in certain episodes of game and standard } \\
\text { situations; unwillingness to take lead on completion of a game } \\
\text { situation. }\end{array}$ \\
\hline "Unsatisfactory" & 2 (two) \\
\hline & Lack of muscle coordination. \\
\hline
\end{tabular}

The main condition for the implementation is determination and evaluation of the orientation on the sports ground level and the level of development of volleyball players speed-power and strength qualities development on a scale from one to five points, which mainly evaluates the success of combining the demonstration of power and speed qualities of an athlete.

Further perfections of volleyball techniques contribute to the increase in efficiency of volleyball players' competitive activity.

\section{REFERENCES}

1. Avramova N.V., Funina E.E., Frolov E.V. Increase of efficiency of competitive activity of highly skilled volleyball players. Pedagogikopsihologicheskie I medico-biologicheskie problemy fizicheskoj kul'tury I sporta $=$ Pedagogicopsychological and medico-biological problems of physical culture and sport. 2011; 4(21): 149-154. (In Russ., In Engl.)

2. Avramova N.V. Variability of motor actions of volleyball players. Fizicheskaya kul'tura: vospitanie, obrazovanie, trenirovka. 2012; 1: 42-44 (In Russ.).

3. Avramova N.V., Nazarenko L.D. Formation of the ability to predict motor actions of 15-17-yearold volleyball players. Fizicheskaya kul'tura: vospitanie, obrazovanie, trenirovka. 2012; 2: 34-36 (In Russ.).

4. Avramova N.V., Nazarenko L.D. Tests and criteria of estimating the skills for programming motor actions of 15-17-year-old volleyball players. Pedagogiko-psihologicheskie I medicobiologicheskie problemy fizicheskoj kul'tury I sporta $=$ Pedagogico-psychological and medicobiological problems of physical culture and sport. 2012; 2(23): 10-16 (In Russ., In Engl.).

5. Balsevich V.K. Ontokineziologiya cheloveka [Ontokinesiology of the human]. Moscow: Theory and practice of physical culture. 2000: 275 .

6. Glinskaya E.G. Improvement of volleyball techniques. Fizicheskaya kul'tura v shkole. 2006; 5: 33-36 (In Russ.). 
7. Demidenko O.V. Modeling of the process of developing movement accuracy of volleyball players with mass athletic titles. Candidate's thesis. Moscow. 2007: 22.

8. Denisov M.V. Conjugate method as a factor contributing to the optimization of the process of improving the elements of volleyball technique. Teoriya I praktika fizicheskoj kul'tury = Theory and practice of physical culture. 2007; 4: 40-41 (In Russ., In Engl.).

9. Kamalieva G.A., Kuznetsova Z.M. Model of training volleyball players to overcome obstacles and difficulties unexpectedly arising in competitive activity. Pedagogiko-psihologicheskie I medicobiologicheskie problemy fizicheskoj kul'tury I sporta $=$ Pedagogico-psychological and medicobiological problems of physical culture and sport. 2011; 2(19): 38-44 (In Russ., In Engl.).

10. Kamalieva G.A. Modeling of competitive obstacles and difficulties as intellectual tasks for theoretical practice of volleyball players. Sovremennye tehnologii fizicheskogo vospitaniya I sporta studencheskoj molodezhi: materialy Vserossijskoj uchebno-metodicheskoj konferencii
[Modern technologies of physical education and sports of student youth: materials of the all-Russian educational and methodical conference]. Ufa: UGNTU. 2011: 101-104 (In Russ.).

11. Kamalieva G.A. Strategies used by volleyball players in extreme situations. Uchenye zapiski Al'met'evskogo gosudarstvennogo neftyanogo instituta: vol. IX. 2011: 357-360 (In Russ.).

12. Araujo, R., Afonso, J., Mesquita, I. Proceedural knowledge, decision - making and game performance analysis in female volleyball's attack according to the player's experience and competitive success. International Journal of Performance Analysis in Sport. 2011; 11: 1-13.

13. Lee, S. M. Does your eye keep on the ball? The strategy of eye movement for volleyball defensive players during spike serve reception. International Journal of Applied Sports Sciences. 201; 22: 128137.

14. Botelho, S., Afonso, J., Araujo, R., Mesquita, I. Procedural knowledge of female volleyball players in defensive actions. Differences across three levels of experience. Portugues Journal of Sports Sciences. 2011; 11: 41.

\section{Submitted: 20.08.2019}

Author's information:

Nadezda V. Makarova - Candidate of Pedagogics, Pskov State University, 1800oo, Russia, Pskov, Lenin square, House 2, e-mail: avramova-84@mail.ru

Aleksey I. Kardashevskiy - Candidate of Pedagogics, Samara State Technical University, 443100, Russia, Samara, Molodogvardejskaya str., House 244, email: Aik1780@yandex.ru

Evgeniya G. Kozhevnikova - Candidate of Technical Sciences, Samara State Technical University, 44310o, Russia, Samara, Molodogvardejskaya str., House 244, email: kozheg@mail.ru 